\title{
Decision Support: A New Approach to Making the Best Healthcare Management and Policy Choices
}

\author{
Jonathan Lomas
}

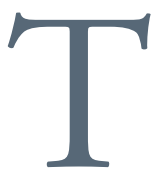

here are at least three reasons why distilling the messages from research is becoming a specialized role. First, there has been an enormous growth in the research enterprise and the resulting publications. This makes it impossible for fellow researchers, never mind those working in healthcare, to keep up with what is going on. Second, not all research is created equal, and it requires some skill to sort the wheat from the chaff before making the "summary loaf" from the best ingredients. Third, there are many spin doctors of research in whose interests it is to do partial summaries that favour their own product or ideology. These can only be countered by those who seek out all the relevant research, favourable or not, and aggregate it into an impartial summary. This approach provides a powerful tool for healthcare managers and policy makers who are searching for ways to improve the system but unsure of where to get or how to assess the deluge of research available.

There is no doubt, therefore, of the value of summarizing with integrity the key messages from research, particularly as this improves the chances that the research might get used! Nevertheless, there is debate about how to do it and, therefore, who should be part of this specialist role in healthcare. Much of the debate focuses on where the role of research and researchers stops and where the role of the system and those working in it starts. Is summarizing research for use in the health system a technical exercise reserved for skilled specialists in the research world? Or is it a social change exercise where the world of ideas learns to dance with the world of context and values?

The answer to this balance is likely different if the intent is to summarize clinical rather than management or policy relevant research. Medical interventions lend themselves to evaluation in a consistent way with a limited number of methodologies. Summary in this case is more about data aggregation and presentation than about data interpretation. Specialists in describing the data can carry the day. Research to inform management strategy and policy prescription demands more varied approaches and draws on a multitude of methodologies. Careful and context-dependent data interpretation is crucial, and those working in the system are often more skilled at this than those collecting the data. The need is for more collaboration between the data collectors (researchers) and the data interpreters (decision-makers).

Hence, the methods used by evidence-based medicine to collect and summarize research are far from the best way to approach summarizing research for managers and policy makers. This is why the Canadian Health Services Research Foundation (CHSRF) collaborated in 2003 with the Service Delivery and Organization (SDO) part of England's National Health Service (NHS) Research and Development program on the Methods of Synthesis for Managers and Policy Makers project (see www.chsrf.ca/funding_opportunities/commissioned_research/projects/background_e.php). The results of this project informed the new approach recently adopted by CHSRF to summarize research messages and develop recommendations for health system managers and policy makers. Before describing this approach, it is useful to review how we got to where we are today in the science of research summary.

Not all research is created equal, and it requires some skill to sort the wheat from the chaff before making the "summary loaf" from the best ingredients.

\section{A Brief History of Research Summary}

The first to see the value of a specialized research summary role were two Harvard psychologists, David Light and Richard Pillemer, who, 23 years ago, wrote the book Summing $U_{p}$ : The Science of Reviewing Research (1984). Since then, however, medicine has taken the lead, with global leadership shared by the United Kingdom and Canada. In 1989, Ian Chalmers from the United Kingdom and Murray Enkin from Canada created, with Marc Keirse from Holland, the first ever systematic compilation of research knowledge for a medical specialty area: Effective Care in Pregnancy and Childbirth. This turned out to be the forerunner to the Cochrane Collaboration, created to 
summarize in systematic reviews the global body of randomized controlled trial research in every clinical area.

In parallel, the movement of evidence-based medicine emanating from McMaster University in the 1980s gave rationales, encouragement and support for the increased use of systematic reviews, with Andy Oxman and Gordon Guyatt (1988) writing seminal pieces on the science of research overviews.

The early tools of these practitioners were meta-analyses, effect sizes and odds ratios. A simple summary statistic captured the effectiveness, or otherwise, of numerous clinical interventions. To the uninitiated non-researcher, however, the meaning of these statistics was not obvious - the summary was too terse and the applicability to specific patient circumstance was unclear. Thus were born clinical guidelines, often adapted locally, with more text and interpretation, as well as more efforts to market their use - what has become known as knowledge translation.

A little more than 10 years ago, the popularity of evidencebased medicine spread beyond the clinical world to management and policy. The tipping point in Canada was the 1997 report of the prime minister's National Forum on Health, which declared evidence-based decision-making (not just medicine) one of the four priorities for healthcare. This spawned an era where many of the tools of evidence-based medicine were tried for management and policy.

Unfortunately, the nature of the relevant research for management and policy was sharply different from that of clinical medicine. Social science research on such things as leadership, governance, change management, nurse retention and teamwork did not lend itself easily to the summary tools developed for randomized controlled trials of drugs, devices and other interventions.

At about the same time, the clinical guidelines movement was realizing that focusing on just the clinicians was achieving little without taking account of the context in which they worked. To quote the godfather of the clinical guidelines and systematic review movement, Canadian Cochrane Collaboration lead Jeremy Grimshaw, "despite 30 years of research in this area, we still lack a robust, generalisable, evidence base to inform decisions about strategies to promote the introduction of guidelines or other evidence-based measures into practice" (Grimshaw et al. 2004). The professional and management structure of clinicians' workplaces and the policy environment created by government are also powerful influences on what they do. Hence, even in the clinical world, an appreciation has emerged for the importance of evidence-based management and policy.

\section{CHSRF's Approach: Synthesis Rather than Summary} CHSRF's approach to extracting key messages from research for managers and policy makers takes account of this evolution in thinking as well as the experience with and lessons learned from our Policy Synthesis program started in 1999. The approach has the aim of what researcher Nick Mays and colleagues call "decision support" as opposed to "knowledge support." For them, the "distinction is between an exercise that is confined to summarizing the evidence (the 'Knowledge Support' approach) and one that includes some or all of the remaining analytical tasks required to reach a decision in the particular policy or management context (the 'Decision Support' approach)" (Mays et al. 2005). For CHSRF, the distinction is even more fundamental. It is the difference between summarizing research for researchers and synthesizing evidence (broader than just research) for decision-making. Thus, the approach recognizes that synthesis requires judgment and interpretation; summary and knowledge support are largely descriptive.

\section{Is summarizing research ... a technical} exercise reserved for skilled specialists in the research world? Or is it a social change exercise where the world of ideas learns to dance with the world of context and values?

Simply by adopting this decision support objective a series of assumptions automatically underpin the design of the new CHSRF synthesis process:

- It answers system-driven questions finalized into a feasible scope of work through collaborative discussions between relevant decision-makers and researchers.

- It recognizes multiple types of evidence, not just research.

- It includes four major phases of work that build on each other: defining the scope of review, summarizing the research, drawing out implications from the research and creating recommendations for management or policy.

- It creates feasible and implementable recommendations by using a deliberative process that allows decision-makers and researchers to pool their judgments in interpreting and synthesizing both the research and other forms of evidence.

The foundation's decision support synthesis program builds on its history of "linkage and exchange" by recognizing the relative expertise of researchers and decision-makers in a collaborative process that gives due to weight to each. Although both sides are involved at all stages, researchers take the driver's seat in the middle phases when the focus is on summarizing and extracting implications from research. The decision-makers are at the wheel at the start when the scope and question are defined and at the end when recommendations for management and policy are created. The result of this two-way collaboration is timely, relevant and applicable decision support informed by 
the very best evidence available. For researchers struggling to get evidence used to inform healthcare improvements and for managers and policy makers trying to make sense of research findings crowding their workspaces - both good and bad - this new approach offers a way forward. More importantly, it holds out the real promise of a healthcare system that is better organized, managed and delivered to Canadians.

For more details on this new approach or for the CHSRF's help in creating a decision support synthesis, see www.chsrf. caldss. HQ

\section{Bibliography}

Chalmers, I., M. Enkin and M. Keirse. 1989. Effective Care during Pregnancy and Childbirth. Oxford: Oxford University Press.

Culyer, A. and J. Lomas. 2006. "Deliberative Processes and EvidenceInformed Decision-Making in Health Care - Do They Work and How Might We Know?” Evidence and Policy 2(3): 357-71.

Greenhalgh, T. and J. Russell. 2006. "Reframing Evidence Synthesis as Rhetorical Action in the Policy Making Drama." Healthcare Policy 1(2): 34-42.

Grimshaw, J.M., R.E. Thomas, G. MacLennan, C. Fraser, C.R. Ramsay, L. Vale, P. Whitty, M.P. Eccles, L. Matowe, L. Shirran, M. Wensing, R. Dijkstra and C. Donaldson. 2004. "Effectiveness and Efficiency of Guideline Dissemination and Implementation Strategies." Health Technology Assessment 8(6): iii-iv, 1-72.

Lavis, J. 2006. "Moving Forward on Both Systematic Reviews and Deliberative Processes." Healthcare Policy 1(2): 59-63.

Lavis, J., H. Davies, A. Oxman, J.L. Denis, K. Golden-Biddle and E. Ferlie. 2005. "Towards Systematic Reviews that Inform Health Care Management and Policy-Making." Journal of Health Services Research and Policy 10(Suppl. 1): 35-48.

Lavis, J.N., H.T.O. Davies, R.L. Gruen, K. Walshe and C.M. Farquhar. 2006. "Working within and beyond the Cochrane Collaboration to Make Systematic Reviews More Useful to Healthcare Managers and Policy Makers." Healthcare Policy 1(2): 21-33.

Light, D. and R. Pillemer. 1984. Summing Up: The Science of Reviewing Research. Boston: Harvard University Press.

Lomas, J. 2005. "Using Research to Inform Healthcare Managers' and Policy Makers' Questions: From Summative to Interpretive Synthesis." Healthcare Policy 1(1): 55-71.

Lomas, J. 2006. "Whose Views Count in Evidence Synthesis? And When Do They Count?” Healthcare Policy 1(2): 55-57.

Mays, N., C. Pope and J. Popay. 2005. "Systematically Reviewing Qualitative and Quantitative Evidence to Inform Management and Policy-Making in the Health Field." Journal of Health Services Research and Policy 10(Suppl. 1): 6-20.

National Forum on Health. 1997. Canada Health Action: Building on the Legacy. Volume I - The Final Report. Ottawa: Government of Canada.

Oxman, A.D. and G.H. Guyatt. 1988. "Guidelines for Reading Literature Reviews.” Canadian Medical Association Journal 138(8): 697-703.

Pawson R., T. Greenhalgh, G. Harvey and K. Walshe. 2005. "Realist Review - A New Method of Systematic Review Designed for Complex Policy Interventions." Journal of Health Services Research and Policy 10(Suppl. 1): 21-34.

Pope, C., N. Mays and J. Popay. 2006. "Informing Policy Making and Management in Healthcare: The Place for Synthesis." Healthcare Policy 1(2): 43-48.

Roger, R. 2006. "A Decision-Maker's Perspective on Lavis and Lomas." Healthcare Policy 1(2): 49-54.

\section{About the Author}

Jonathan Lomas is the inaugural and former CEO of the Canadian Health Services Research Foundation.

\section{Thank you}

for supporting Breakfast with the Chiefs

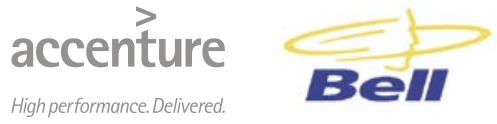

Longwoods Publishing Enabling Excellence

\section{HayGroup}

\section{Transforming health care organizations} through a focus on strategy, people, work and performance:

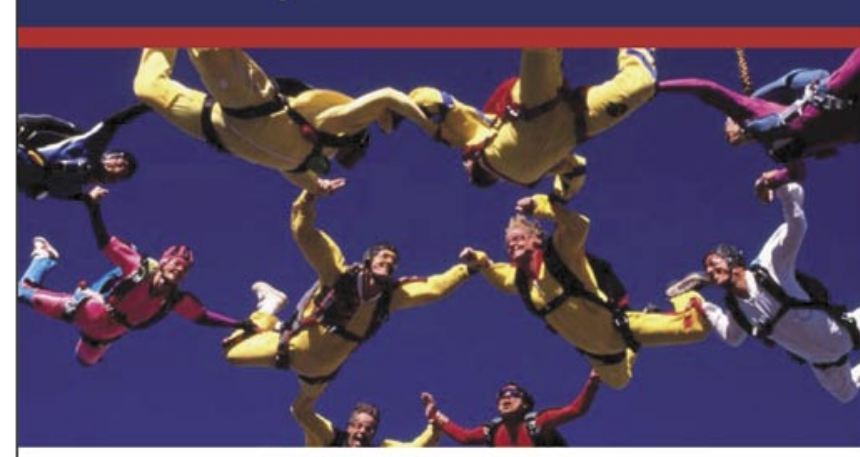

- Planning

- Operational Improvement

- Organizational Effectiveness

- Human Resources Management

- Reward Programs

Contact:

Mark Hundert, National Director

Tel: (416) 868-1371 Fax: (416) 868-0362 